\title{
ФОРМИРОВАНИЕ И РАЗВИТИЕ ПОЛОЖИТЕЛЬНОЙ САМООЦЕНКИ ЛИЦ С ОВЗ И ИНВАЛИДОВ КАК УСПЕШНОСТЬ УЧЕБНОГО ПОЗНАНИЯ
}

\author{
Покровская Татьяна Мирушевна \\ к.пед.н. \\ ГБПОУ ЛО «Бегуницкий \\ агротехнологический техникум»
}

\begin{abstract}
Аннотация: Данное исследование по формированию положительной самооценки лиц с ОВ3 и инвалидов в профобразовании выполнено на основе психолого-педагогического исследования автора по развитию самооценки студентов вузов. Теоретико-экспериментальная работа позволила получить необходимые данные не только для успешности обучения, но и формирования профессиональных компетенций.

Ключевые слова: Самооценка, лица с OB3, инвалиды, профобразование, СПО, профессиональная, компетенция, развитие, формирование, учебная, сформированность, самосознание, «Я-идеальное» и «Я-реальное», особенность.
\end{abstract}

\section{FORMATION AND DEVELOPMENT OF POSITIVE SELF-ESTEEM OF PERSONS WITH DISABILITIES AND DISABLED PEOPLE AS THE SUCCESS OF EDUCATIONAL COGNITION}

Pokrovskaya Tatiana Mirushevna 
Abstract: This study on the formation of positive self-esteem of people with disabilities and disabled people in vocational education was carried out on the basis of the author's psychological and pedagogical research on the development of selfesteem of university students. Theoretical and experimental work allowed us to obtain the necessary data not only for the success of training, but also for the formation of professional competencies.

Key words: Self-esteem, persons with disabilities, disabled, vocational education, vocational education, professional, competence, development, formation, educational, formation, self-awareness, "I am ideal" and "I am real", feature.

Формированию у студентов с ОВ3 и инвалидов интеллектуальных знаний и умений, целостной системы интегративных общепрофессиональных знаний, профессионально значимых качеств содействуют: интегративные учебные курсы лекций, лабораторных, практических занятий, междисциплинарное учебное проектирование, диагностика сформированности уровня знаний обучаемых. По мнению Ю.Н. Семина учебная информация по своему содержанию и форме должна соответствовать достижениям современной науки и применению методов научного познания и логическим формам мышления, мысленном эксперименте, моделировании, абстрагировании, системном анализе, алгоритмировании, логикоматематической формализации (Ю.Н. Семин, 2001).

Существующая образовательная система в профессиональном образовании не полностью содействует формированию у лиц с ОВ3 и инвалидов системного познания окружающей действительности, так как знания, взятые из разных дисциплин, не соединяются в единую научную картину мира.

Возрастающий объем научной и учебной информации превышает психические возможности запоминания личности с такими особенностями. 
В теории и практике обучения данной категории лиц существует противоречие между коллективным способом усвоения знаний и профессиональными компетенциями, индивидуальным формированием способностей, личностных качеств, опыта.

Годы обучения в техникуме совпадают с возрастной периодизацией, которая отличается сложностью становления личностных черт. (Б.Г.Ананьев, А.В.Дмитриев, З.Ф.Есарева, И.С.Кон, В.Т. Лисовский и др. В силу психофизиологических особенностей способность лиц с ОВ3, инвалидов к сознательной регуляции собственного поведения недостаточно развита. Самооценивание происходит в результате сравнения «Я-идеального» и «Яреального», в то время как «Я-идеальное» и «Я-реальное» не оценено самой личностью. Соответственно, главной задачей педагогов и психологов является воспитание свободной в духовном развитии, творческой, самостоятельной, адекватно оценивающей себя личности.

Самооценка играет огромную роль на протяжении всей жизни индивида. Являясь важной частью самосознания, она определяет место личности с ОВЗ и инвалида в окружающей мире, определяет характер взаимоотношений с родителями, сокурсниками, преподавателями.

Недостаточная теоретическая и практическая разработанность данной проблемы не дает возможности определить функции индивидуализации в изменении самого учебного процесса в СПО для лиц с ОВ3 и инвалидов, характерные особенности воспитания активной и творческой самостоятельности личности

Цель исследования: выявить влияние профессиональной системы обучения на самооценку лиц с ОВ3 и инвалидов.

Объект исследования: самооценка лиц с ОВ3 и инвалидов.

Предмет исследования: развитие самооценки лиц с ОВЗ и инвалидов в системе профессионального образования. 
Гипотеза исследования: развитие самооценки лиц с ОВ3 и инвалидов системе среднего профессионального образования станет более эффективным, если оно будет проходить в условиях индивидуализации обучения профессионального образования.

Теоретическую и методологическую базу исследования составляют: принципы гуманизации образования (М.Н.Берулава, И.В. Бестужев-Лада, Ю.П. Ветров, И.В. Дубровина, Н.Д. Никандров, И.А. Зимняя, В.П. Зинченко, И.С. Якиманская и др.), идеи личностно-ориентированного подхода (А. Адлер, Айзенк, Ш.Бюлер, К.Гольдштейн, Кэттел, А.Маслоу, Р.Мей, Д.Олпорт, А.В.Петровский, К.Роджерс, К.Хорни, Г.Юнг); теоретические положения о развитии самооценки в юношеском возрасте(А.В.Захарова, А.П.Кепалайте,А.И.Липкина, Л.М., В.С.Магун, С.Е. Репкина, М.Розенберг, Е.Т.Соколова, Л.С.Солнцева, К.Р.Ставицкий, В.В.Суворова, Е.О. Федотова, М.Б.Федотова, Шевлсон и др.).

Задачи исследования:

1. Исследовать соотношение «Я-идеального» в оценке студента с ОВ3 и инвалида педагогами и «Я-реального» студента как фактора развития самооценки обучающегося в учебно-воспитательной деятельности профобразования

2. Выделить профессионально значимые качества личности («профиль») обучаемого в интерпретации педагогов, ориентированные на ценности профессиональной системы обучения.

3. Выявить влияние данного проектного «профиля» на формирование самооценки.

Методы исследования: теоретический анализ и синтез, абстрагирование и конкретизация, аналогия, моделирование; эмпирические частные (анкетирование, изучение литературы, документов и результатов деятельности, авторский опросник для выявления уровня самооценки, метод 
семантического дифференциала, модифицированный автором, экспертный анализ) и общие (педагогический эксперимент, опытная работа, изучение и обобщение педагогического опыта) методы. Количественный анализ полученных данных осуществлялся с помощью методов математической статистики.

Научная новизна исследования состоит в том, что определена значимость самооценки в личностном развитии обучающегося с ОВ3 и инвалидов, представленного индивидуальной системой знаний и эмпирических представлений об особенностях жизнедеятельности в образовательной среде; определены качественные особенности развития самооценки в профобразовании.

Теоретическая значимость исследования состоит в том, что полученные данные позволяют выявить возможности обучения лиц с ОВ3 и инвалидов в профессиональном обучения для развития адекватной самооценки студентов. Полученные данные могут быть значимыми для развития педагогики профессионального образования

Практическая значимость выполненного исследования состоит в том, что его результаты могут быть использованы педагогами для совершенствования процесса обучения лиц с ОВЗ и инвалидов в СПО в плане развития личностных качеств обучающихся и, в частности, их самооценивания.

Достоверность научных результатов исследования обеспечивается системным рассмотрением проблемы, опытно-педагогической проверкой теоретических разработок и подтверждением результатов в ходе их апробации; использованием методов сбора и проверки эмпирического материала; многоаспектностью обработки данных, включающих качественные и количественные оценки. 
Экспериментальная база исследования. Исследование проводилось на базе ГБ ПОУ ЛО «Бегуницкий агротехнологический техникум».

Апробация результатов исследования. Материалы исследования обсуждались на заседаниях предметно-цикловой комиссии общеобразовательных дисциплин, на конференциях

Публикации: по материалам исследования имеются следующие публикации:

1. Т.М. Покровская. Методическая разработка по теме: «Самооценивание обучающихся как одна из новых форм оценивания образовательных результатов» 2019 2020, представленная на региональном форуме педагогических идей и инноваций как победитель.

2. Покровская Т.М. кандидат педагогических наук, преподаватель Блинова М.В. преподаватель экономических дисциплин ГБПОУ ЛО «Бегуницкий агротехнологический техникум» «Саморазвитие как фактор процесса профессионального становления студентов СПО в формате дистанционного обучения» статья в ЛОИРО ноябрь-декабрь 2020

3. Покровская T.M.

«ПЕДАГОГИЧЕСКИЕОСНОВЫ ОБУЧЕНИЯ СТУДЕНТОВ С ОВЗ И ИНВАЛИДОВ в журнале научных публикаций «Вопросы педагогики». ISSN 2518-1793 В 33 Вопросы педагогики: журнал научных публикаций. - №09 (сентябрь) /Науч.-инф. издат. Центр « Институт стратегических исследований. Москва, 2018 г.

4. Покровская Т.М.ЭКСПЕРИМЕНТАЛЬНОЕ ИССЛЕДОВАНИЕ САМООЦЕНКИ И УРОВНЯ ПРИТЯЗАНИЙ ЛИЦ С ОВЗ И ИНВАЛИДОВ В УЧЕБНО-ВОСПИТАТЕЛЬНОМ ПРОЦЕССЕ» ISSN 2518-1793 В 33 ВопросЫ педагогики: журнал научных публикаций. - №09 (сентябрь) /Науч.-инф. издат. Центр « Институт стратегических исследований. Москва, 2018 г. 
5. Всероссийский конкурс творческих педагогов России при поддержке Министерства образования и науки России Федерации публикация статьи « Применение пословиц и басен в практике обучения английскому языку», Москва, 2017 г.

Структура: данное исследование состоит из трех глав и заключения, списка литературы.

Часть 1.Теоретические и практические основы обучения лиц с OBЗ и инвалидов в профессиональном обучении

Самоценность обучающихся с ОВЗ и инвалидов, развитие их личности в социуме, в собственном духовном мире- одна из задач педагогов и психологов профобразования.

Соответственно и подготовка будущего профессионала должна включать в себя компоненты:

1. Значимую роль личности с ОВЗ и инвалида в профессиональной и социально-экономической сфере;

2. Самореализацию и сознание собственной уникальности;

3. Целенаправленную и ответственную деятельность;

4. Развитие самооценки, предполагающая наличие условий для самореализации субъекта обучения.

Современное обучение лиц с ОВЗ и инвалидов в СПО на современном этапе становится культурно насыщенным и реализуется с помощью инновационных технологий. При таком подходе педагогика является составной частью общечеловеческой культуры, в основе которой находятся такие выделенные Ш.А. Амонашвили и В.И. Загвязинским механизмы развития, как:

1. Механизмы взаимного дополнения, устанавливающие связь социализации личности, идентификации в определенной культуре, индивидуализации, индивидуального становления и самоопределения; 
2. Механизмы продуктивного доминантного преобразования, предусматривающие зону ближайшего развития, становления личности в индивидуальной и коллективной деятельности;

3. Механизмы опосредования, предполагающие самоопределение молодого человека в совместной деятельности;

4. Механизмы продуктивно- творческой интеграции, основополагающими факторами которых являются сотрудничество, сотворчество, равноправный диалог в процессе социокультурной интеграции.

Практика обучения лиц с ОВЗ и инвалидов как инновационная педагогическая идея должна включать в себя эмпирические и теоретические описания педагогической действительности, социопрактические содержания, такие обобщенные характеристики субъектов учебно-воспитательного процесса, как психологические характеристики преподавателя и студента, социальное происхождение, материальные условия студента, уровень мастерства педагога и т.д.

Целостная система подготовки специалистов как педагогическая концепция индивидуализации обучения в рамках профессионального образования включает в себя:

- разработанность социальных, философских, психологических идей об индивидуальности развивающейся личности, ее индивидуализации;

- совокупность психолого-педагогических концепций, создающих методы изучения психических и личностных особенностей студентов;

- комплекс дидактических принципов, помогающих индивидуализировать учебно-воспитательный процесс;

- средства индивидуализации обучения, обеспечивающие адаптивные дидактические методы и формы организации обучения студентов.

Часть 2. Индивидуализация обучения лиц с ОВ3 и инвалидов в системе среднего профессионального образования 
Одним из функциональных компонентов индивидуализации обучения является согласование самооценок и притязаний субъекта с его возможностями и окружающей средой при полной самореализации личности. Результатом этого согласования является успешность, положительная результативность обучения, которая достигается психологами и педагогами с помощью таких принципов как:

- стимулирование мотивации заинтересованности в обучении;

- развитие активности, сознательности, познавательности, самостоятельности студента;

- направленность учебно-воспитательного процесса на всестороннее, гармоничное развитие молодого человека;

- обеспечение субъекту самоконтроля в обучении;

- сочетание фронтальных, групповых индивидуальных форм обучения;

- помощь в осуществлении выбора субъектом характера собственного поведения;

- построение учебно-воспитательного процесса на основе целей обучения с учетом наблюдаемых действий обучаемых;

- построение индивидуального режима и темпа учебной деятельности;

- помощь в самостоятельном планировании субъектом процесса обучения.

В мотивационно-целевой основе учения студентов СПО основной целью является профессиональная подготовка специалистов. Наиболее обобщенной формой отношения молодого человека к будущей профессии является профессиональная направленность, которая складывается из личных оценок степени значимости различных аспектов, содержания, условий осуществления профессиональной деятельности. 
Предметом оценки значимости будущей профессии для студента являются: работа с людьми, соответствие индивидуальных способностей, характера выбранному делу. Отношение студентов к профессии, а соответственно и к целям профессионального образования выступает в качестве средства их достижения, впоследствии образует учебную мотивацию.

Различные виды мотивации определяют отношение обучающегося к учебным предметам, представляющую будущую профессиональную деятельность. Практически каждая учебная дисциплина оценивается обучаемым с точки зрения профессионального, познавательного интереса, качества преподавания, собственных возможностей, определяющих степень трудности усвоения предмета. В отношении степени профессиональных качеств личности существует совпадение и расхождение мнений студентов и преподавателей.

Из проведенного Н.В. Комусовой исследования (1982) по развитию мотивации к овладению профессией в период обучения следует, что профессиональная значимость учебных дисциплин оценивается студентами выше, чем познавательный интерес к ним. Это подчеркивает отсутствие совпадения между личными интересами студентов и профессиональными целями обучения, реализующимися через учебные предметы.

Формированию положительной мотивации к учению и овладению профессией для лиц с ОВ3 и инвалидов определяется уровнем организации учебного процесса, оказывающим влияние на субъективную оценку обучающимися организации учебных занятий, научной работы, профессионализм преподавателей, создание благоприятной психологической атмосферы в группе.

Учебно-познавательная деятельность студента СПО осуществляется с помощью учебных действий, навыков, приемов, поисковых задач, 
исследовательских методов под руководством педагога, выступающего посредником между обучаемым и научным знанием.

По мнению А.Маслоу «после удовлетворенности потребности в принадлежности появляется потребность уважения к себе для наличия положительных реакций со стороны окружающих, положительного самооценивания, ощущения благополучия и довольства собой. В самом верху иерархии потребности находится потребность в самоактуализации и развитии своего потенциала. «Человек должен стать тем, кем он может стать» (Маслоу, 1954).

Часть 3. Экспериментальное исследование самооценки как успешности учебной мотивации

В рамках данной проблематики было проведено экспериментальное исследование влияние самооценки на успешность учебной мотивации студентов с ОВ3 и инвалидами.

Основной целью диагностики самооценки было выявление исследуемых параметров в зависимости от оценок педагогов, используемых по отношению к обучаемым. Профиль необходимых профессиональных знаний; потребность в самостоятельном пополнении знаний; способность к самостоятельным обобщениям и выводам; умение ставить и решать проблемы профессиональной самооценки обучающихся определил характер дифференциации и уровень самооценки в баллах.

В качестве критериев сформированности самооценки студентов в сфере учебной деятельности выступают: оценка собственных профессиональных перспектив; способность к самостоятельному изучению литературы; уверенность в наличии необходимых профессиональных знаний; потребность в самостоятельным обобщениям и выводам; умение ставить и решать проблемы. 
В целях выявления профессиональной самооценки студентов с ОВ3 и инвалидов был проведен опрос для выявления уровня сформированности профессиональной самооценки.

Авторский опросник Т.М.Ноздриной (Покровской)

для выявления уровня сформированности профессиональной самооценки студента, адаптированный для лиц с ОВ3 и инвалидов

1. Думаю, что

а) моя карьера состоится;

б) моя карьера вряд ли состоится.

2. Думаю, что

а) умею самостоятельно изучать литературу;

б) еще не умею самостоятельно изучать профессиональную литературу.

3. Мне кажется, что я

а) имею необходимые знания, чтобы моя карьера состоялась;

б) не имею пока необходимых знаний, чтобы моя карьера состоялась.

4. Полагаю, что

а) у меня есть потребность в самостоятельном понимании своих знаний;

б) у меня пока нет потребности в самостоятельном пополнении своих знаний.

5. Думаю, что

а) умею делать самостоятельные обобщения и выводы;

б) не умею делать самостоятельные обобщения и выводы.

6. Думаю, что

а) умею самостоятельно ставить проблемы и решать их;

б) не умею самостоятельно ставить проблемы и решать их.

При интерпретации результат оценивался следующим образом: от 0 до 2 - низкий уровень самооценки, от 3 до 4 - средний уровень самооценки, 
от 5 до 6 - высокий уровень самооценки.

Было исследовано 60 человек. В результате исследования уровня сформированности профессиональной самооценки обнаружились следующие результаты: высокий уровень самооценки - у 22 обучаемых, средний уровень самооценки - у 28, низкий уровень самооценки - у 12.

Проведя данное экспериментальное исследование можно предположить, что самооценка обучающегося является не только значимым фактором в личностном и профессиональном развитии, но и одним из факторов успешности учебного познания.

Заключение

Проведя данное исследование, можно сформулировать выводы, подтверждающие гипотезу исследования:

1. «Я-идеальное», проектируемое педагогами выступает в качестве не только социокультурного проекта развития личности, но и в соотношении с качествами «Я-реальное» определяет самооценивание данной группы обучающихся.

2. «Профиль идеального студента с ОВ3 в интерпретации современных педагогов профессионального образования включает в себя следующие личностные качества: потребность в самостоятельной постановке проблемной ситуации и их решении; помощь сокурсникам в коллективной учебной и творческой деятельности; умение делать самостоятельные обобщения и выводы.

3. Анализ проблемы обучения студентов с ОВЗ и инвалидов в СПО показал, что развитие самооценки данной группы обучающихся является значимым качеством личности для профессионального и личностного роста специалиста. 


\section{Список литературы}

1. Адлер А. Индивидуальная психология//История зарубежной психологии: тексты/Под ред. Гальперина, А.Н. Ждан.-М.,1986.

2. Амонашвили Ш.А., Загвязинский В.И. Паритеты, приоритеты и акценты//Педагогика, 2000, № 2 .

3. Ананьев Б.Г. Избранные психологические труды: в 2 т./под ред. Бодалева А.А. и др.-М., 1980.

4. Ананьев Б.Г. Человек как предмет познания .-Л., 1969.

5. Анастази Анна, Урбина Сюзан. Психологическое тестирование. 7-ое издание. Серия «Мастера психологии».- СПб.: Питер.-2001.

6. Берулава М.Н. Теория и практика гуманизации образования.Москва: Гелиос АРВ, 2000

7. И.В. Бестужев-Лада. Образование: традиции и перспективы //Вопросы философии.-1999.-№3Д

8. Захарова А.В. Генезис самооценки/Автореферат докт. Дис.-М., 1989.

9. Зимняя И.А. Педагогическая психология. - М., 1997.

10. Зинченко В.П. Аффект и интеллект в образовании//Педагогика. 1997. -№2.

11. Климов Е.А. Психология профессионального самоопределения. Ростов-на- Дону: «Феникс», 1996.

12. Кон И.С. Психология ранней юности. - М.: Просвещение, 1989.

13. Липкина А.И., Рыбак Л.А. Критичность и самооценка в учебной деятельности. - М., 1968.

14. Магун В.С. Оценки самооценки в структуре индивидуальности //Психодиагностические методы в комплексном и лонгитюдном исследовании студентов. -Л., 1976.

15. Мерлин В.С. Психология индивидуальности. - М., 1996//Избранные психологические труды под ред. Климова Е.А. 
16. Ноздрина Т.М. (Покровская Т.М.) Развитие самооценки студентов в процессе вузовского обучения. - Сочи: НОЦ РАО, 2003.

17. Реан А.А. Агрессия и агрессивность личности//психологический журнал. - 1996. - №5

18. Ревская Н.Е. Психология и педагогика/ Краткий конспект курса лекций. - СПб: ООО «Изд-во «Альфа». - 2001.

19. Соколова Е.Т. Самосознание и самооценка при аномалиях личности. - M., 1980.

20. Шадриков В.Д. Проблема системогенеза профессиональной деятельности. - М., 1982.

21. Экспериментальное изучение положительных и отрицательных эмоций. А.П. Кепалайте, В.В. Суворова// Вопросы психологии. - 1992. - №2

22. Якунин В.А. Педагогическая психология. - Санкт-Петербург, 1998. 